\title{
A noção de representação em Freud e sua relação com o modelo psicossomático
}

\author{
Renan Custódio do Nascimento ${ }^{l}$
}

\begin{abstract}
Resumo - O presente artigo apresenta uma resenha da Dissertação de Mestrado em Psicologia: A Noção de representação nos escritos iniciais de Freud e a construção de um novo modelo do psíquico, defendida na Universidade Católica de BrasíliaUCB, sob orientação da Prof ${ }^{a}$. Dr ${ }^{\mathrm{a}}$. Maria Aparecida de Paiva Montenegro. É uma pesquisa conceitual com um exame epistemológico, em que se objetiva identificar o surgimento de uma nova concepção de psicológico - o psicossomático, a partir dos escritos iniciais de Freud, baseado no paradigma vigente - o psíquico pensado a partir do somático, numa equivalência entre o somático e o psíquico.
\end{abstract}

Palavras-chave: representação; Freud; modelo psicossomático.

\section{A representation concept of Freud and his relation with the psychosomatic model

\begin{abstract}
The present work presents a Psychology Master dissertation - "A representation concept of Freud's first writings and a new model buildy, presented at Brasilia's Catholic University-UCB under professor Dra. Maria Aparecida de Paiva Montenegro supervision. This is a conceptual research of an epistemological exam which aims the identification of a new psychological concept and the Freud's first writings, from the former paradigm - the psychic thought from the somatic, an equivalence between the psychic and somatic.
\end{abstract}

Key words: representation; Freud; psychosomatic model.

A noção de representação nos escritos iniciais de Freud marca uma importante mudança na forma de se pensar a constituição do psíquico, do somático e, sobretudo, da própria relação entre ambas. Na verdade, a teoria freudiana da representação pode ser pensada como o pilar sobre o qual se erige todo o arcabouço conceitual da psicanálise. ${ }^{2}$ Conseqüentemente, Freud acaba por tocar e, em cer-

\footnotetext{
${ }^{1}$ Renan C. do Nascimento-Psicólogo clínico, especialista em psicologia hospitalar, com formação em medicina psicossomática, formação em hipnose ericksoniana, especialista em educação sexual, mestre em psicologia, e professor de psicofisiologia naFaculdade de Ciências da Saúde do Uniceub.

${ }^{2}$ Psicanálise, aqui, deve ser entendida estritamente como o produto das formulações teóricas e clínicas de Freud, não incluindo as reformulações e alterações introduzidas por psicanalistas posteriores.
} 
to sentido, estremecer o fundamento de toda a Filosofia Moderna, a saber, a noção de subjetividade, igualmente imbricada em uma teoria da representação.

Com efeito, se com Descartes se inaugura uma subjetividade epistemológica - o sujeito como substância impessoal e universal, capaz de obter certeza daquilo que conhece por meio da formulação de representações claras e distintas depreendida, por assim dizer, de um diálogo privado travado pela consciência com ela mesma, com a teoria freudiana emerge uma outra subjetividade. Mais precisamente, tem-se, consolidada no pensamento de Freud, uma noção de subjetividade eminentemente psicológica e, em princípio, pessoal, particular. É nessa psicologizacão da subjetividade que reside a provocação freudiana, uma vez que ela indica o comprometimento daquilo que se conhece com o desejo inconsciente daquele que conhece - donde a impossibilidade de se obter a certeza do conhecimento, no âmbito de um diálogo privado. Em outras palavras, se há um componente inconsciente intervindo no processo do conhecimento, a noção de subjetividade freudiana vem mostrar que a suposta unidade do sujeito epistemológico é falsa. Por conseguinte, há, na própria constituição do sujeito, uma vez pensado como um sujeito cindido, uma impossibilidade estrutural tanto para o autoconhecimento quanto para o conhecimento do mundo. Nesse sentido, não só a constituição do sujeito freudiano depende da intervenção de uma alteridade, como toda a possibilidade de conhecimento está condicionada a essa confrontação.

Assim sendo, não é possível, em Freud, uma racionalidade pura, apriorística, cujos princípios universais podem ser obtidos pelo movimento reflexivo da consciência e pelas construções da representação (posição idealista). Tampouco é possível uma racionalidade depreendida a partir de uma representação que tãosomente espelha os objetos tal qual eles são no mundo (posição empirista anterior a Stuart Mill). Antes, a noção freudiana de representação remete a um complexo, que, em princípio, funda-se sobre uma fonte somática, algo da natureza de uma necessidade. Esta, ao despertar a atenção de um outro, promove a referida relação com a alteridade, a partir da qual se fixa a representação propriamente dita. A representação, portanto, é um composto da apresentação psíquica de uma necessidade somática, dotada de sentido pela mediação do outro. Nessa perspectiva, não parece demasiado supor que a racionalidade freudiana não está nem no sujeito nem no mundo, pois não preexiste a uma espécie de negação com a alteridade. Consequientemente, a certeza do conhecimento de si e do mundo não pode ser obtida senão por meio de uma relação com um outro - donde então o papel fundamental conferido pela psicanálise à fala.

O objetivo da dissertação em questão visa mostrar que, à luz da noção de representação, tal como é formulada desde os escritos do período inicial da obra 
de Freud, é possível identificar a emergência de uma nova concepção de psicológico, paralelamente ao paradigma vigente no final do século XIX, segundo o qual o psíquico manteria uma relação de equivalência frente aos processos somáticos. Mais precisamente, pretende mostrar, em torno da noção de representação, a presença de uma espécie de ambigüidade na empresa freudiana de construir uma teoria dos processos mentais. Tal ambigüidade, por sua vez, pode ser formulada nos seguintes termos: de um lado, Freud adere ao modelo em voga àquela época, de acordo com o qual o psíquico é pensado de forma naturalizada. Em outras palavras, o psíquico é suposto como um campo de estudo das ciências naturais, o que implica, neste caso, submetê-lo ao método de investigação próprio de tais ciências. De outro lado, ele aponta para uma concepção de psíquico que adquire um outro estatuto - o da significação -, que não se subsume no plano do meramente físico.

À medida que a teoria da representação vai se consolidando, Freud eximese, gradativamente, de discorrer sobre os aspectos biológicos e mecânicos, de descrever os processos que circundam a esfera somática e a psíquica. E, dessa forma, o campo da representação ganha o cenário principal da reflexão psicanalítica.

Nessa perspectiva, o texto de Freud priorizado neste exame foi estrategicamente escolhido: trata-se do Projeto de uma Psicologia ${ }^{3}$, escrito em 1895 e publicado apenas postumamente, em 1950. Dado que consiste em um empreendimento, por assim dizer, malsucedido (apesar de muito em voga àquela época), de descrever os processos mentais como processos neuronais, tem-se, nas contradições e problemas presentes nessa obra, um vasto terreno de investigação da ambigüidade suposta no pensamento de Freud.

A partir dos entraves conceituais do Projeto, pretende-se mostrar que tudo se passa como se Freud - apesar de concordar com a legitimidade da descrição dos processos psíquicos em termos neurofisiológicos - fosse, pouco a pouco, constatando que tal redução, pelo menos naquele momento, não se mostraria plausível. Desse modo, passaria a inserir, no próprio texto do Projeto, descrições que lançam mão de uma noção de psíquico que não se reduz ao plano dos processos neurofisiológicos, como é o caso da noção de representação. Assim procedendo, Freud teria inaugurado uma nova forma de se pensar o psíquico, ainda que, durante muitos anos, sustentasse a crença de que tal recurso seria provisório - segundo ele, até que a Bioquímica avançasse a ponto de ser capaz de descrever os processos mentais em termos puramente fisicalistas.

\footnotetext{
${ }^{2}$ Freud, S. (1895)Projetode uma Psicologia, com traduçãode OsmyrFaria Gabbi Junior, pela ImagoEditora, 1995.
} 
Não é objetivo do presente estudo avaliar a legitimidade dessa aposta freudiana. Ou seja, não se pretende adentrar no exame propriamente dito da redutibilidade dos processos psíquicos a descrições do tipo fisicalista. Antes, supõese tão-somente que Freud, ao adiar o pagamento de tal aposta para o futuro, abre um novo campo de descrição dos processos mentais, tornando precisamente essa mesma aposta, cada vez mais discutível.

Dessa forma, a partir dos problemas evidenciáveis nessa obra, não parece injustificado identificar uma mudança de paradigma no modo de se pensar as relações entre o somático e o psíquico. Em outros termos, ao propor noções psicológicas que não se reduzem a descrições em termos somáticos, Freud promove uma espécie de inversão nessas relações: ao invés de pensar o psíquico como mera expressão de funções somáticas, o próprio campo do somático passa a poder ser pensado como objeto de representação. Essa mudança é particularmente importante no interior da obra freudiana, pois Freud estava inserido em um contexto de investigação neurológica de vanguarda para a época, com o rigor positivista de quem buscava um entendimento dos processos psíquicos fundamentado no que acreditava ser uma descrição livre de contradições.

Curiosamente, contudo, Freud elabora um percurso no qual gradativamente lança mão de noções que se descolavam da neurologia, ou seja, de uma orientação psicofísica. E, assim, abre campo para uma perspectiva propriamente psicológica, inaugurando uma linguagem acerca desses fenômenos, em termos de representação. À luz dessa noção, Freud propõe um entendimento da função mental distinto do determinismo causal das operações fisiológicas. Desse modo, a construção da noção de representação marca o rompimento gradual de Freud em relação ao pensamento de Charcot, Bernhein e Breuer, cuja influência conceitual foi marcante no percurso inicialmente realizado por ele.

A nova postura conceitual de Freud construída a partir do Projeto de uma Psicologia (1895), é solidificada em sua obra A Interpretação dos Sonhos (1900), em que ele apresenta definitivamente o modelo de sua tópica. Nesse sentido, há uma inversão no modo de se pensar o somático e o psíquico: ao invés de pensar o psíquico como mera expressão do somático, o próprio campo do somático passa a ser pensado como objeto da representação. Essa inversão marca a possibilidade de um entendimento da linguagem e dos sintomas como uma expressão da vida anímica, mediada pelos processos secundários (pré-consciente e consciente), e arquitetadas pelo desejo - a partir do inconsciente (processo primário). Assim, a consciência seria um conjunto de qualidades que uma representação de objeto pode apresentar ao ligar-se a outra representação (de palavra).

O que possibilita uma análise mais profunda das relações constitutivas entre a fala, o sintoma e a ação, que pode resultar numa organicidade psicofisiológica 
saudável, e/ou patológica. Com efeito, a construção da noção de representação possibilita uma compreensão dos processos e distúrbios psicossomáticos, nos quais o requinte da construção dos sintomas revela o grau de singularidade na complexidade da constituição do sujeito, por meio dos processos representacionais, ditos psicossomáticos.

No início do Projeto, Freud pretende explicar as relações de sentido (intencionalidade), a partir das ocupações da quantidade; ao final, ele aponta para a possibilidade de submeter o curso da quantidade às relações de sentido. Assim, o sentido determina o lugar da quantidade. Esse tópico constitui um dos principais alcances da teoria freudiana da representação. Esse novo modelo do psíquico baseado na noção de representação, no qual a palavra passa a ser pensada como a unidade funcional da_fala, sendo constituída por uma representação complexa que associa a significação a elementos visuais, auditivos e cinestésicos, marca o rompimento gradual de Freud em relação às concepções neurológicas do psiquismo, ampliando o espectro de possibilidades de se pensar o paradigma psicossomático.

\section{Referências bibliográficas}

FREUD, S. Projeto de uma psicologia - obras isoladas de Freud. Trad. Osmyr Faria Gabbi Junior. Rio de Janeiro: Ed. Imago, 1995.

LEBRUN, G. L'idée d'épistémologie. MANUSCRITO. Revista de filosofia; Universidade Estadual de Campinas, Vol.1, nº 1, p.7-21, UNICAMP Campinas- S.P., Outubro de 1977.

MASSON, J. M. A. Correspondência completa de Sigmund Freud para Wilhelm Fliess (1887-1904). Trad. Vera Ribeiro. Rio de Janeiro: Imago Editora, 1986.

NASCIMENTO, R. C. A noção de representação nos escritos iniciais de Freud e a construção de um novo modelo do psíquico. Dissertação de Mestrado apresentada ao Programa de Pós-graduação em Psicologia da Universidade Católica de Brasília-UCB, Brasília, julho-2001. 